\title{
Linear Lichen Planus: Two Case Reports
}

\author{
(D) Gülhan Gürel, ${ }^{1}$ (b) Sevinç Şahin, ${ }^{2}$ (D) Emine Çölgeçen¹ \\ 'Department of Dermatology, Bozok University School of Medicine, Yozgat, Turkey \\ ${ }^{2}$ Department of Pathology, Bozok University School of Medicine, Yozgat, Turkey
}

\section{ABSTRACT}

Lichen planus (LP) is an idiopathic inflammatory skin disease which affects the skin, mucosa, nails, and hairs of middle-aged individuals. Linear lichen planus (LLP) is a rare variant of LP characterized by pruritic, lichenoid appearance, violaceous-color papules in a linear pattern. About 0.24 to $0.62 \%$ of patients with LP have been reported to have LLP. In cases with LP, linear lesions can be post-traumatically seen as widespread generalized eruptions (Koebner phenomenon) and as zosteriforms on herpes infection as the Wolf's isotopic response. However, LLP indicates the presence of spontaneous LLP lesions which follow Blaschko's lines without any previous association with trauma or herpes infection. Herein, we present two cases with LLP and emphasize the rarity of these cases and the importance of linear lesions in the differential diagnosis.

Keywords: Dermatosis, lichen planus, skin diseases

\section{INTRODUCTION}

Lichen planus (LP) was first described in 1869 by Erasmus Wilson. ${ }^{[1]}$ It is mostly seen in adults aged 30 to 60 years and affects 0.14 to $0.8 \%$ of the population. LP is classified according to the location, distribution, and morphology of the lesion and nearly 20 clinical forms have been described as eruptive, localized, annular, linear, hypertrophic, nodular, atrophic, bullous, erosive, actinic, palmoplantar, oral and follicular forms. ${ }^{[2]}$

Please cite this article as: Gürel G, Şahin S, Çölgeçen E. Linear Lichen Planus: Two Case Reports. Anatol J Family Med 2019;2(1):41-4.

Address for correspondence: Dr. Gülhan Gürel. Bozok Universitesi Tip Fakultesi, Dermatoloji Anabilim Dali, Yozgat, Turkey

Phone: +90 5069260596 E-mail:

gulhanozturkgurel@hotmail.com

Received Date: 27.09.2018

Accepted Date: 27.11.2018

Published online: 30.04 .2019

(C)opyright 2019 by Anatolian Journal of Family Medicine -

Available online at

www.anatoljfm.org
Linear lichen planus (LLP) is a rare variant of LP characterized by pruritic, lichenoid appearance, violaceous-color papules in a linear pattern. About 0.24 to $0.62 \%$ of patients with LP have been reported to have LLP. Linear lesions frequently occur in patients with LP and are attributed to scratching as a consequence of severe pruritus (Koebner phenomenon) ${ }^{\left[{ }^{[3]}\right.}$ It is usually seen in a single lane and is more common than Koebner phenomenon. ${ }^{[4]}$ Involvement of the oral mucosa is also common. Lesions may involve other cutaneous (i.e., scalp, hair, and nails) and mucosal sites. ${ }^{[5]}$

Herein, we present two cases with LLP and emphasize the rarity of these cases and the importance of linear lesions in the differential diagnosis.

\section{CASE REPORT}

Case 1 - A 42-year-old man was admitted to our clinic with complaints of itchy eruptions extending from the back of the right leg to the thigh for about one month. No history of disease, trauma, or drug use was reported at the site of the eruptions. His past medical history was non-specific, except for hypertension. The patient was on a drug therapy with candesartan/ 
hydrochlorothiazide. His family history was non-remarkable. Dermatological examination demonstrated linear, purplish-colored papular lesions extending distally from the medial surface of the right thigh of the lower extremity (Fig. 1). Examination of the oral mucosa, hair, nails, and genital mucosa revealed normal findings. Serological tests including hepatitis $B$ and $C$ with normal laboratory values were negative. A lesion punch biopsy was performed. Light microscopic examination of the skin biopsy revealed orthokeratosis on the surface. Wedge-shaped hypergranulosis, apoptotic keratinocytes, irregularities at the rete ridges, focal vacuolar changes in the dermoepidermal junction, and superficial dermis band-like lichenoid chronic inflammatory cell infiltration on the epidermis were observed. No eosinophilic leukocytes associated inflammatory cells were detected. Histopathological findings were consistent with LP (Fig. 2). Based on clinical and histopathological examination, the patient was diagnosed with LLP and local steroidal ointment containing clobetasol propionate treatment was prescribed. The lesions improved within three weeks leaving post-inflammatory hyperpigmentation.

Case 2 - A 43-year-old woman was admitted to our clinic with eruptions on the back of her thigh and leg for about six months. The patient did not complain of any itching on the area of eruption and reported no previous history of trauma or disease. Her medical history and family history were non-remarkable and there was no history of drug use. On admission, she was on a steroid cream for about two weeks which was prescribed by a dermatologist at another center. Dermatological examination demonstrated sporadic post-inflammatory brown-purplish-colored macular lesions starting from the posterior surface of the left thigh and extending linearly to the posterior surface of the leg (Fig. 3). Examination of the oral mucosa, hair, nails, and genital mucosa revealed normal findings. Serological markers of hepatitis were found to be normal and routine laboratory test values were also within normal limits. A lesion punch biopsy was performed. Light microscopic examination of the skin biopsy revealed orthokeratosis and papillomatosis on the surface. Mild irregular acanthosis and sporadic hypergranulosis were observed on the epidermis. Focal vacuolar changes and lymphocyte exocytosis were detected on the epidermal basal layer. Marked melanin incontinence on the superficial dermis and mild perivascular lymphocytic infiltration were observed (Fig. 4). Based on clinical and histopathological examination, the patient was diagnosed with LLP and was advised to continue with the topical steroid treatment due to improvement in the lesions.

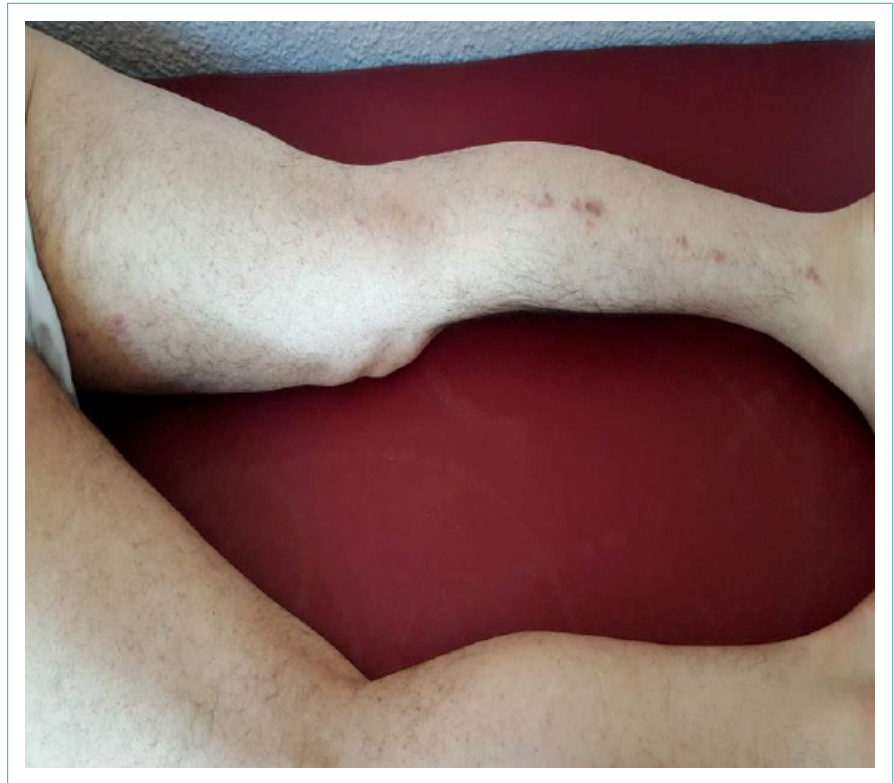

Figure 1. Linear, purplish-colored papular lesions extending distally from the medial surface of the right thigh of the lower extremity.

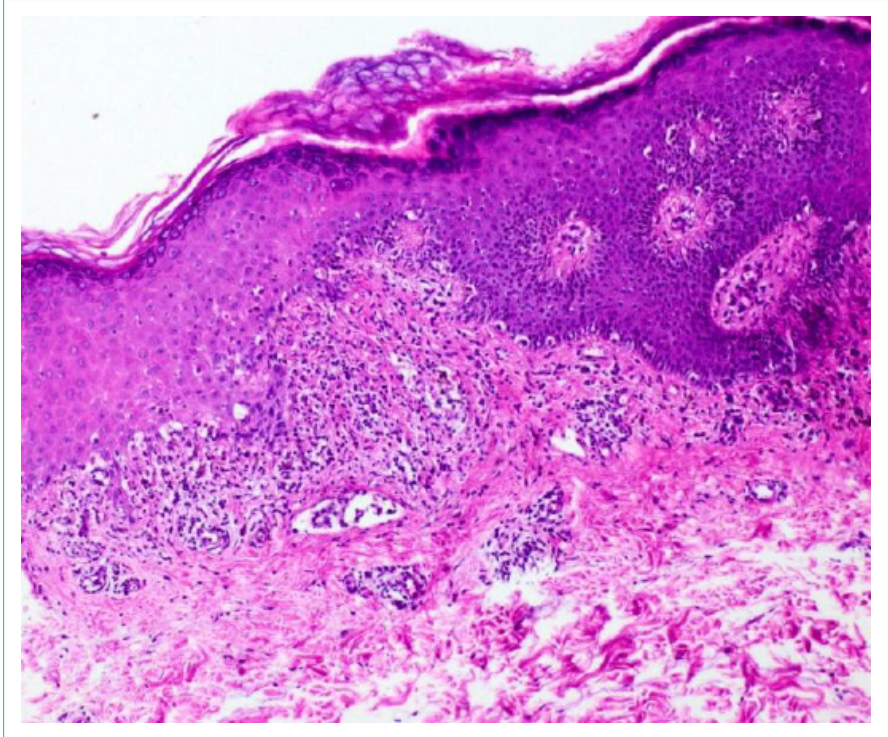

Figure 2. Microscopic appearance of the skin biopsy of Case 1, (Hematoxylin-eosin staining, $\mathrm{x} 100$ ).

\section{DISCUSSION}

In cases with LP, linear lesions can be post-traumatically seen as widespread generalized eruptions (Koebner phenomenon) and as zosteriforms on herpes infection as the Wolf's isotopic response. ${ }^{[6,7]}$ However, LLP indicates the presence of spontaneous LLP lesions which follow Blaschko's lines without any previous association with trauma or herpes infection. ${ }^{[2]}$ During early foetal development a clone of cells migrate to certain areas of the integument congruent with the Blaschko lines. This subpopulation of cells is believed to acquire distinct qualities allowing for certain 


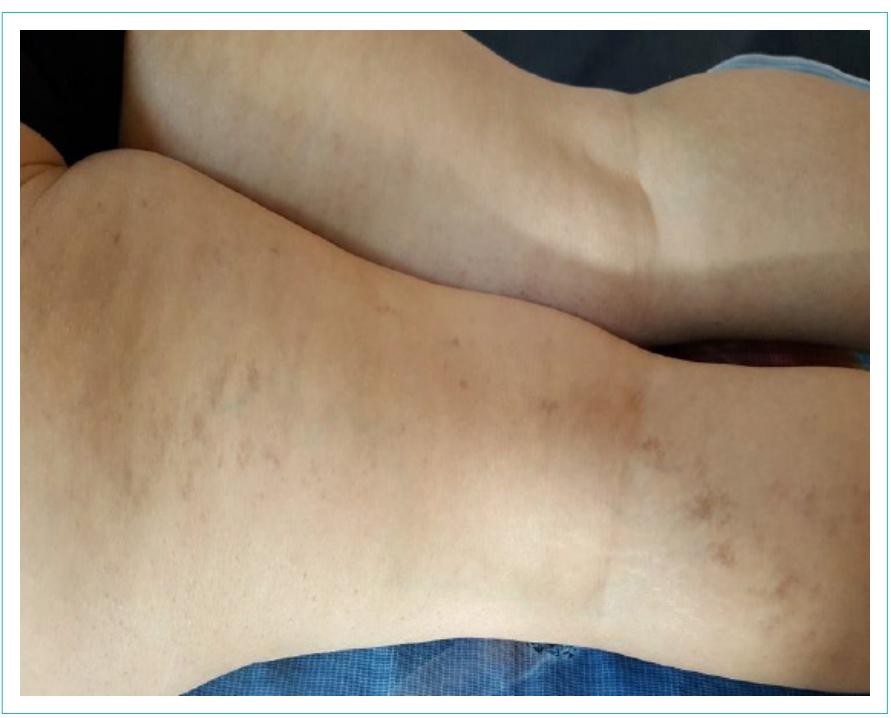

Figure 3. Sporadic post-inflammatory brown-purplish co-lored macular lesions starting from the posterior surface of the left thigh and extending linearly to the posterior surface of the leg.

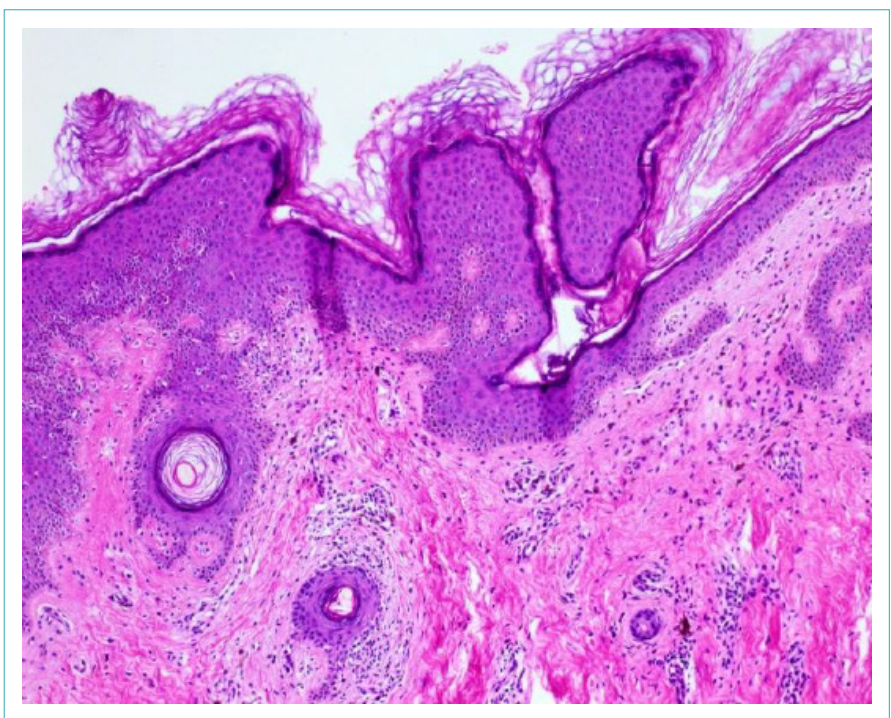

Figure 4. Histopathological appearance of the skin biopsy of Case 2, (Hematoxylin-eosin staining, $\mathrm{x} 100$ ).

dermatosis to occur exclusively along these lines. ${ }^{[3]}$

Although the terms LLP and zosteriform LP can be used interchangeably, certain differences exist in their etiology. In a study, Mizukawa et al. investigated varicella zoster virus antigens in zosteriform LP and LLP patients by in vivo immunohistochemical procedures and found these antigens in the eccrine epithelium of patients with zosteriform LP in the patients with LLP. ${ }^{[8]}$

The authors suggested that zosteriform LP and LLP were different entities and that there might be some differences in the pathogenesis. In out both cases, lesions were located ipsilaterally and demonstrated a linear distribu- tion morphologically consistent with the Blaschko's line. No history of trauma or herpes infection was reported in both patients.

The etiology is not clearly known, but it is thought to be associated with chronic active hepatitis, hepatitis B vaccine, viral and bacterial antigens, trauma, drugs and various autoimmune diseases. ${ }^{[9]}$ Histological findings of LLP have been shown to be similar to those of LP. Therefore, lichen striatus, linear lichen nitidus, inflammatory linear verrucous epidermal nevus (ILVEN), linear psoriasis, and linear DarierWhite disease should be considered in the differential diagnosis of LLP. ${ }^{[9]}$ Lichen striatus is a unilateral linear eruption usually found in the extremities. It is most commonly observed in children, with exocytosis in the histopathology, and non-specific findings such as intense inflammatory infiltrates around adnexal structures. ${ }^{[10,11]}$ In its histopathology, lichen nitidus is described as a disease characterized by granulomatous infiltration in the papillary dermis. ${ }^{[12]}$ In addition, ILVEN is usually present during birth. Histopathological evaluation shows parakeratosis, Munro's microabscess formation, and mild perivascular lymphocytic infiltration in the dermis. ${ }^{[13]}$ Psoriasis can be distinguished clinically and histologically with the appearance of Blaschko's lines. ${ }^{[1]}$ On the other hand, Darier's disease is histologically characterized by dyskeratosis and acantholysis. ${ }^{[12]}$

In the treatment of LP, options include topical, intra-lesional, and systemic corticosteroids, retinoids, phenytoin, dapsone, griseofulvin, hydroxychloroquine, metronidazole, azathioprine, cyclophosphamide, levamisole, interferon alpha-2b, cyclosporine, tetracycline, itraconazole, and phototherapy ${ }^{[9,10,12]}$ Our both cases each responded to topical corticosteroids treatment.

\section{CONCLUSION}

In conclusion, LLP should bring to mind the presence of Blaschko's lines, rather than a dermatomal distribution. We report these cases due to their rarity and to highlight the importance of linear lesions in the differential diagnosis.

\section{Disclosures}

\section{Conflict of Interest: None.}

Peer-review: Externally peer-reviewed.

Financial Disclosure: None.

Authorship contributions: Concept - G.G., S.Ş.; Design - G.G., S.Ş., E.Ç.; Supervision - G.G., S.Ş.; Fundings - G.G.; Materials - G.G., S.Ş.; Data collection \&/or processing - G.G.; Analysis and/or interpretation - G.G., S.Ş., E.Ç.; Literature search - G.G., S.Ş.; Writing G.G., S.Ş.; Critical Review - G.G., S.Ş., E.Ç. 


\section{REFERENCES}

1. Kabbash C, Laude TA, Weinberg JM, Silverberg NB. Lichen planus in the lines of Blaschko. Pediatr Dermatol 2002;19:541-5.

2. Kalkan G, Takcı Z, Şimşek GG. Lineer liken planuslu bir olgu sunumu: Doğru adlandırmanın kullanılması. J Clin Exp Invest 2013;4:529-31. [CrossRef]

3. Hartl C, Steen KH, Wegner H, Seifert HW, Bieber T. Unilateral linear lichen planus with mucous membrane involvement. Acta Derm Venereol 1999;79:145-6. [CrossRef]

4. Koryürek ÖM, Karataş A, Boyraz N, Ekşioğlu HM. Zosteriform Liken Planuslu Bir Olgu Sunumu. Dermatoz 2011;2:335-6.

5. Weston G, Payette M. Update on lichen planus and its clinical variants. Int J Womens Dermatol 2015;1:140-9. [CrossRef]

6. Türel A, Öztürkcan S, Şahin MT, Türkdoğan P. Wolf's isotopic response: a case of zosteriform lichen planus. J Dermatol 2002;29:339-42. [CrossRef]

7. Shemer A, Weiss G, Trau H. Wolf's isotopic response: a case of zosteriform lichen planus on the site of healed herpes zoster.
J Eur Acad Dermatol Venereol 2001;15:445-7. [CrossRef]

8. Mizukawa Y, Horie C, Yamazaki Y, Shiohara T. Detection of varicella-zoster virus antigens in lesional skin of zosteriform lichen planus but not in that of linear lichen planus. Dermatology 2012;225:22-6. [CrossRef]

9. Odom RB, James WD, Berger TG. Lichen planus and related conditions. In: Andrew's diseases of the skin 9th ed. Philadelphia: WB Saunders Company. 2000. p.266-83.

10. Serarslan G, Hakverdi S. Blaschko Çizgileri Dağılımlı İki Lineer Liken Planus Olgusu. Turkderm 2008;42:28-30.

11. Zhang Y, McNutt NS. Lichen striatus. Histological, immunohistochemical, and ultrastructural study of 37 cases. J Cutan Pathol 2001;28:65-71. [CrossRef]

12. Braun-Falco O, Plewig G, Wolff HH, Burgdorf WHC: Dermatology second, completely revised edition. Berlin, Springer-Verlag. 2000. p.709-50. [CrossRef]

13. Lever WF, Schaumung-Lever G. Histopathology of the skin, 7th ed. Philadelphia: JB Lippincott Company. 1990. p.175-6. 